\title{
FORMASI TUMBUHAN HUTAN HUJAN DATARAN RENDAH DI SAMARES KAMPUNG SEPSI DISTRIK BIAK TIMUR, KABUPATEN BIAK NUMFOR
}

\section{(Low Land Rain Forest Stands Formation of Samares in Sepsi Village, East Biak Sub- district, District of Biak Numfor)}

\author{
SOETJIPTO MOELJONO ${ }^{1,2 \bowtie}$, AGUSTINUS MURDJOKO ${ }^{1,2}$, MOH. SHOLEH MARDOYONO $^{2}$, \\ BETTY LIGARTI SILITONGA ${ }^{2}$, LAURA LASAMAHU ${ }^{2}$, TERENIUS KIWO ${ }^{2}$ \\ ${ }^{1}$ Jurusan Kehutanan, Fakultas Kehutanan Universitas Papua Manokwari, Papua Barat, 98314. \\ Tlp/Fax: +62986211065. \\ ${ }^{2}$ Program Studi Kehutanan Sekolah Program Pasca Sarjana Universitas Papua Manokwari, Papua Barat, 98314 \\ ${ }^{\square}$ Penulis Korespondensi: Email: s.moeljono@unipa.ac.id \\ Diterima: 25 Sept 2020| Disetujui:15 Okt 2020
}

\begin{abstract}
Abstrak. Penelitian ini bertujuan untu memperoleh informasi terkait struktur dan komposisi vegetasi tumbuhan pada tingkat semai, pancang, tiang dan pohon dengan pendekatan parameter indeks nilai penting di hutan Samaris kampung Sepse. Pengamatan dilakukan di distrik Biak Timur dengan menggunakan metode kuadran pada empat plot pengamatan. Hasil penelitian memperlihatkan komposisi jenis sebanyak 29 jenis dengan komposisi struktur vegetasi yang beragam pada setiap tingkatan pertumbuhannya. Dari nilai INP diketahui jenis Pala hutan (Myristica fatua) dengan INP 54,21\%, selanjutnya diikuti dengan jenis Mansai (Buchanania arborence) dan Mangganipro (Horsfieldia sp).

Kata kunci: Tegakan hutan, hutan dataran rendah, struktur dan komposisi, tingkat pertumbuhan, analisis vegetasi
\end{abstract}

\begin{abstract}
This study aims to obtain information regarding structure and composition of plant vegetation at the whole stages: seedling, sapling, pole, and tree through importance value index parameter approach in Samares forest, Sepse village. The observation was taken place in west Biak island by applying quadrant method in the four observative plots. The result pointed out the total species composition found about 29 species with a quite diverse forest vegetation, including its structure and composition for each growing stage. From the importance value index, it can be seen the highest score of IVI was Myristica fatua (IVI of 54.21\%), then followed by Buchanania arborence and Horsfieldia sp.
\end{abstract}

Keywords: Forest stands, low land forest, structure and composition, growing stage, vegetation analysis

\section{PENDAHULUAN}

Hutan adalah suatu kesatuan ekosistem berupa hamparan lahan berisi sumberdaya alam hayati yang didominasi oleh pepohonan dalam komunitas alam lingkungannya yang tidak dapat dipisahkan antara satu dengan yang lainnya (UU No. 18 Tahun 2013). Hutan di Indonesia mempunyai tiga tipe ekosistem alami, yaitu hutan monson, hutan pegunungan, dan hutan dataran rendah (Pamulardi 1999). Hutan dataran rendah terletak pada ketinggian 0 - 1000 meter dari permukaan laut dan merupakan bagian terbesar hutan yang 
mencakup kawasan yang paling luas di Indonesia. Hutan dataran rendah ditandai dengan adanya tumbuhan pemanjat pohon yang banyak dan lebat, pohon-pohon berbanir besar dan banyak pohon-pohon dengan batang yang tinggi bulat mempunyai kulit yang halus (Anwar et al. 1992). Di hutan dataran rendah banyak terdapat spesies pohon anggota famili Dipterocarpaceae, selain itu terdapat famili Lauraceae, Myrtaceae, Miristicaceae, dan Ebenaceae (Soerianegara \& Indrawan 2016).

Menurut Soerianegara dan Indrawan (2016), hutan dataran rendah dapat dikelompokkan kedalam dua kategori, yakni hutan dataran rendah Dipterocarpaceae yang didominasi oleh genus Shorea, Dipterocarpus, Dryobalonops, Cotylelobium dan Hopea. Sedangkan hutan dataran rendah Non-Dipterocarpaceae yang didominasi oleh genus Anisoptera, Hopea, Shorea, dan Vatica (Mongabay 2012). Hutan dataran rendah Dipterocarpaceae menyebar di wilayah Indonesia bagian barat khususnya di pulau Kalimantan dan Sumatera, dan Malaysia, Brunei, Filipina (Ashton 1982). Sementara hutan dataran rendah NonDipterocarpaceae di temukan di belahan Indonesia bagian timur Sulawesi, Maluku, Bali-Lombok, dan Papua-Nugini (Purwaningsih 2004).

Hutan dataran rendah adalah salah satu jenis tegakan yang perlu diteliti struktur dan komposisinya dikarenakan areal ekosistem dataran rendah memiliki kekayaan keanekaragaman hayati dan tingkat endemisme yang tinggi. Namun demikian, pada umumnya hutan ini telah banyak mengalami degradasi karena dekatnya pemukiman masyarakat sehingga dapat rentan kehilangan sumberdaya genetika.

Salah satu hutan dataran rendah yang ditemukan di Pulau Biak adalah hutan dataran rendah di Samares kampung Sepse dimana kawasan ini merupakan wilayah kawasan hutan yang secara legal formal telah disahkan oleh Menteri Kehutanan berdasarkan Keputusan Menhut RI No. SK.6544/Menhut-II/Reg.4-1/2014 menjadi Rencana Pengelolaan Hutan Jangka Panjang (RPHJP) periode 2015-2024 KPHL Model Biak dalam salah satu program kegiatan pemanfaatan hutan di bidang jasa lingkungan.

Analisis vegetasi terhadap hutan perlu dilakukan, selain untuk mengetahui keanekaragaman hayati yang terdapat di hutan tersebut sehingga mempermudah didalam melakukan pemeliharaan dan pemberdayaan hutan. Untuk keperluan analisis vegetasi diperlukan data jenis tumbuhan, diameter dan tinggi untuk menentukan indeks nilai penting dari penyusun komunitas hutan tersebut. Dengan analisis vegetasi dapat diperoleh informasi kuantitatif tentang struktur dan komposisi suatu komunitas tumbuhan (Heriyanto 2007). Dari uraian di atas maka dapat dilakukan pengamatan mengenai bagaimana keanekaragaman hayati dan struktur vegetasi (frekuensi, kerapatan, dominansi, dan Indeks Nilai Penting) di hutan dataran rendah, Samares, Sepse Biak Numfor untuk di jadikan pertimbangan dalam perencanaan lebh jauh dalam proses pemgembanganya.

Analisis vegetasi ini dilakukan dengan maksud untuk mengetahui struktur vegetasi pertumbuhan tumbuhan pada tingkat semai, pancang, tiang dan pohon dengan melihat Indek Nilai Penting, dengan tujuan untuk memberikan informasi komposisi keragaman sehingga untuk mempermudah proses pengembangan dan pemberdayaan hutan Samares kampung sepse sebagai salah satu pemanfaatan hutan di bidang jasa lingkungan.

\section{METODE PENGAMATAN}

Pengamatan di lakukan pada bulan September 2019 di hutan dataran rendah Samares kampung Sepse distrik Biak Timur 
yang terletak pada ordinat geografis $\mathrm{S}=01^{\circ}$ 02.784'dan $\mathrm{E}=136^{\circ} 10.375^{\prime}$.

\section{Bahan dan Alat}

Bahan yang di gunakan dalam pengamatan ini adalah semua jenis pohon pada tingkatan semai, pancang, tiang dan pohon yang terdapat pada petak plot pengamatan. Sedangkan alat yang digunakan dalam pengamatan ini adalah adalah meteran untuk mengukur lebar plot dan panjang garis transek, pita ukur untuk mengukur diameter batang pohon, haga meter untuk mengukur tinggi pohon, kompas untuk menentukan arah garis transek, dan alat tulis untuk mencatat data.

\section{Metode}

Metode yang di gunakan adalah metode kuadran yaitu dengan mengambil contoh pada luasan 1 haktar pada kawasan hutan setelah itu dibuat 4 plot pengamatan dimana jarak antar plot sejauh $50 \mathrm{~m}$ dan di setiap plot di buat pengamatan dengan petak ukuran $1 \mathrm{~m} \times 1 \mathrm{~m}$ untuk semai atau anakan, $5 \mathrm{~m} \times 5 \mathrm{~m}$ untuk pancang, $10 \mathrm{~m} \times 10 \mathrm{~m}$ untuk tiang dan $20 \mathrm{~m} \times$ $20 \mathrm{~m}$ untuk pohon. Desain metode pengamatan bias di lihat pada gambar 1 di bawah ini.

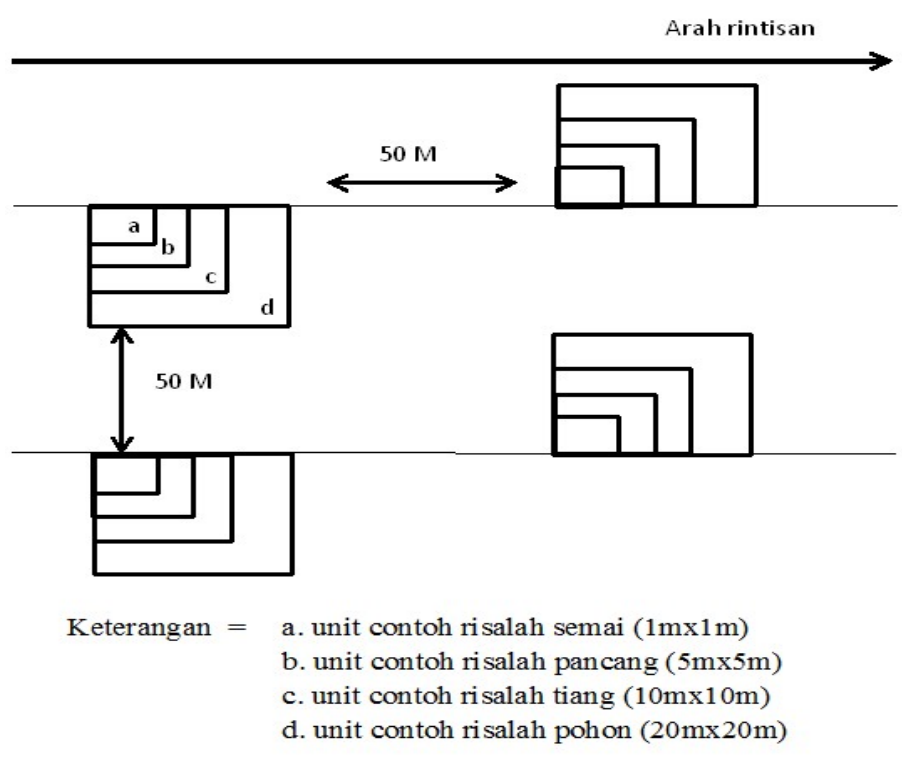

Gambar 1. Desain plot pada metode pengamatan

Untuk melihat struktur vegetasi menggunakan analisis data yang diperoleh dengan melihat variabel kerapatan, dominansai, frekuensi dan nilai penting. Dengan rumusan sebagai berikut :

Kerapatan (K) Dan Kerapatan Relatif (KR)

$$
K=\frac{\text { Jumlah Individu suatu Jenis }}{\text { Luas Petak Contoh }}
$$

$$
\begin{aligned}
& \text { KR - } \quad \text { K Suatu Jenis } \times 100 \% \\
& =\quad \text { K Seluruh Jenis }
\end{aligned}
$$

Frekuensi (F) Dan Frekuensi Relatif (FR)

$$
\begin{aligned}
& F=\frac{\text { Jumlah Petak ditemukannya suatu jenis }}{\text { Jumlah seluruh petak contoh }} \\
& F R=\underline{\text { F Suatu Jenis }} \quad \times 100 \%
\end{aligned}
$$


F Seluruh Jenis

Dominansi (D) Dan Dominansi Relatif (DR)

$$
\begin{aligned}
& D=\frac{\text { Jumlah Individu suatu Jenis }}{\text { Luas Petak Contoh }} \\
& D R=\frac{\text { DSuatu Jenis }}{\text { DSeluruh Jenis }} \times 100 \%
\end{aligned}
$$

Nilai Penting (NP) Atau INP

$$
I N P=K R+F R+D R
$$

\section{HASIL DAN PEMBAHASAN}

\section{Komposisi jenis}

Hasil pengamatan analis vegetasi dan analisis data ditemukan adanya perbedaan struktur dan komposisi jenis penyusun kawasan hutan dataran rendah Samares kampung Sepse. Berdasarkan struktur vegetasi dapat dilihat dari tingkat pertumbuhan yang meliputi semai, pancang, tiang dan pohon, selain itu struktur hutan juga dapat dilihat dari jumlah struktur yang tumbuh selama pengamatan dilakukan. Berdasarkan analisis vegetasi yang dilakukan pada kawasan hutan dataran rendah Samares kampung Sepse ditemukan struktur vegetasi yang meliputi tingkat semai, pancang, tiang dan pohon dengan komposisi jenis sebanyak 29 jenis, dimana setiap tingkat pertumbuhan di temukan 15 jenis tingkat semai atau anakan, 23 jenis tingkat pancang, 11 jenis tingkat tiang dan 18 jenis tingkat pohon. Berikut tabel struktur vegetasi dari pohon dan tumbuhan yang ditemukan di hutan dataran rendah Samares Kampung Sepse Distrik Biak timur.

\section{Analisis Vegetasi Tingkat Semai/anakan}

Hasil analisis vegetasi kerapatan, kerapatan relatif, frekwensi dan frekwensi relatif pertumbuhan jenis pada tingkat semai di sajikan pada table 1 .

Tabel 1. Struktur vegetasi dari semai/anakan yang ditemukan di hutan dataran rendah Samares kampung Sepse distrik Biak Timur

\begin{tabular}{llllllr}
\hline NO & \multicolumn{1}{c}{ JENIS } & NAMA DAERAH & K & KR & F & FR \\
\hline 1. & Timonius sp & Sumber & 2.500 & 2.17 & 0,25 & 5 \\
2. & Chrysophyllum sp & Aibidisen & 7.500 & 6.52 & 0.75 & 15 \\
3. & Instia bijuga & kayu besi & 2.500 & 2.17 & 0.25 & 5 \\
4. & Macaranga sp & Mandus & 2.500 & 2.17 & 0.25 & 5 \\
5. & Burcklea sp & Kaum & 5.000 & 4.35 & 0.5 & 10 \\
6. & Mallotus sp & Barnasem & 2.500 & 2.17 & 0.25 & 5 \\
7. & Aghatis sp & Damar & 2.500 & 2.17 & 0.25 & 5 \\
8. & Ficus sp & Sasyum & 2.500 & 2.17 & 0.25 & 5 \\
9. & Flaeourtia sp & Aiber & 10.000 & 8.70 & 0.25 & 5 \\
10 & Buchanania & Mansai & 5.000 & 4.35 & 0.25 & 5 \\
11 & Aglaia sp & Langsat hutan & 5.000 & 4.35 & 0.25 & 5 \\
12 & Sphtiostemon & Darmor & 27.500 & 23.91 & 0.5 & 10 \\
13 & Sphatiostemon sp & Parson & 2.500 & 2.17 & 0.25 & 5 \\
14 & Chionanthus sp & Kayu Bram & 2.500 & 2.17 & 0.25 & 5 \\
15 & Garcinia sp & Kamomes & 35.000 & 30.43 & 0.5 & 10 \\
& & & 115.00 & 100 & 5 & 100 \\
\hline
\end{tabular}




\section{Analisis Vegetasi Tingkat Pancang}

Hasil analisis vegetasi kerapatan, kerapatan relative, fkrekwensi dan frekwensi relative pertumbuhan jenis pada tingkat pancang di sajikan pada table 2 .

Tabel 2. Struktur vegetasi dari pancang yang ditemukan di hutan dataran rendah Samares Kampung Sepse Distrik Biak Timur

\begin{tabular}{|c|c|c|c|c|c|c|}
\hline NO & JENIS & NAMA DAERAH & K & $\mathrm{KR}$ & $\mathrm{F}$ & FR \\
\hline 1. & Ficus $\mathrm{sp}$ & Sasyum & 800 & 4.17 & 0.25 & 6.25 \\
\hline 2. & Macaranga sp & Mandus & 800 & 4.17 & 0.5 & 12.5 \\
\hline 3. & Canarium $\mathrm{sp}$ & Nasem & 400 & 2.08 & 0.25 & 6.25 \\
\hline 4. & $\begin{array}{l}\text { Buchanania } \\
\text { arborences }\end{array}$ & Mansai & 800 & 4.17 & 0.5 & 12.5 \\
\hline 5. & Palaquium sp & Nyatoh & 400 & 2.08 & 0.25 & 6.25 \\
\hline 6. & Ochrosia sp & Aibidisen & 400 & 2.08 & 0.25 & 6.25 \\
\hline 7. & Syzygium sp & Jambu Hutan & 800 & 4.17 & 0.5 & 12.5 \\
\hline 8. & Flaeourtia sp & Aiber & 400 & 2.08 & 0.25 & 6.25 \\
\hline 9. & Aghatis sp & Damar & 400 & 2.08 & 0.25 & 6.25 \\
\hline 10. & Calophylum sp & Bintanggur & 800 & 4.17 & 0.25 & 6.25 \\
\hline 11. & $\begin{array}{l}\text { Sphtiostemon } \\
\text { javanensis }\end{array}$ & Darmor & 2800 & 14.58 & 0.25 & 6.25 \\
\hline 12. & Sphatiostemon $\mathrm{sp}$ & Parson & 2400 & 12.50 & 0.25 & 6.25 \\
\hline \multirow[t]{2}{*}{13.} & Garcinia sp & Kamomes & 8000 & 41.67 & 0.25 & 6.25 \\
\hline & & & 19200 & 100 & 4 & 100 \\
\hline
\end{tabular}

Dari hasil analisis vegetasi pada tabel 2, jenis vegetasi dari tegakan pancang yang paling banyak terdapat di daerah area pengamatan adalah jenis kamomes (Garcinia sp.) dan jenis Darmor (Sphtiostemon javanensis) seperti sama halnya pada tingkat semai, baru setelah itu dikuti anakan jenis Parson (Sphatiostemon sp) dan jenis lainnya. Kerapatan relatif pada anakan kamomes (Garcinia Sp) sebesar 41,67 \% mendominasi pada petak plot ke 4 demikian juga kerapatan tegakan pancang Darmor (Sphtiostemon javanensis) sebesar 14,58\% kemudian diikuti jenis lainnya yang kerapatan pertumbuhannya kecil sedangkan, namun dari sisi frekwensi kehadiran pada petak plot kehadiran ketiga jenis tersebut tidak merata dan cendrung terpusat pada salah satu petak plot yang ada, dalam hal ini fkrekwensi kehadiran relatih yang yang tertinggi yaitu jenis Mandus (Macaranga sp), Mansai (Buchanania arborences sp), Jambu Hutan (Syzygium sp) yang memiliki kehadiran relatif sebesar $12,5 \%$ krmudian diikuti oleh jenis lainnya.

\section{Analisis Vegetasi Tingkat Tiang}

Hasil analisis vegetasi kerapatan, kerapatan relative, fkrekwensi dan frekwensi relatif, dominansi, dominansi relatif dan INP pertumbuhan jenis tingkat tiang di sajikan pada table 3. 
Tabel 3. Struktur vegetasi dari tiang yang ditemukan di hutan dataran rendah Samares kampung Sepse distrik Biak Timur

\begin{tabular}{|c|c|c|c|c|c|c|c|c|c|}
\hline NO & JENIS & NAMA DAERAH & $\mathrm{K}$ & $\mathrm{KR}$ & $\mathrm{F}$ & FR & $\mathrm{D}$ & DR & INP \\
\hline 1. & Macaranga $\mathrm{sp}$ & Mandus & 25 & 5.88 & 0.25 & 7.69 & 0.16 & 1.78 & 15.35 \\
\hline 2. & Mallotus sp & Barnesem & 25 & 5.88 & 0.25 & 7.69 & 0.05 & 0.58 & 14.16 \\
\hline 3. & Ficus sp & Sasyum & 25 & 5.88 & 0.25 & 7.69 & 0.08 & 0.91 & 14.48 \\
\hline 4. & Chrysophyllum sp & Ai bedizen & 25 & 5.88 & 0.25 & 7.69 & 0.03 & 0.38 & 13.96 \\
\hline 5. & Sphtiostemon sp & Darmor & 125 & 29.41 & 0.5 & 15.38 & 4.70 & 53.75 & 98.55 \\
\hline 6. & Horsfieldia $\mathrm{sp}$ & Mangganipro & 50 & 11.76 & 0.25 & 7.69 & 2.81 & 32.14 & 51.60 \\
\hline 7. & Calophylum sp & Bintanggur & 50 & 11.76 & 0.5 & 15.38 & 0.12 & 1.42 & 28.57 \\
\hline 8. & Flaeourtia sp & Aiber & 25 & 5.88 & 0.25 & 7.69 & 0.46 & 5.23 & 18.81 \\
\hline 9. & Suodia $\mathrm{sp}$ & Mampros & 25 & 5.88 & 0.25 & 7.69 & 0.07 & 0.82 & 14.39 \\
\hline 10. & Chionanthus sp & Kayu Bram & 25 & 5.88 & 0.25 & 7.69 & 0.11 & 1.20 & 14.78 \\
\hline \multirow[t]{2}{*}{11.} & Sphatiostemon sp & Parson & 25 & 5.88 & 0.25 & 7.69 & 0.16 & 1.78 & 15.35 \\
\hline & & & 425 & 100 & 3.25 & 100 & 8.75 & 100 & 300 \\
\hline
\end{tabular}

Dari hasil analisis vegetasi pada tabel 2, jenis vegetasi dari tegakan tiang yang paling banyak terdapat di daerah area pengamatan adalah jenis Darmor (Sphtiostemon sp), dan diikuti jenis dan Bintangor (Calophylum sp) serta jenis lainnya. Kerapatan relatif pada tegakan tiang Darmor (Sphtiostemon sp) sebesar 29,41\% mendominasi pada petak plot ke 4 dan ke 2, sedangkan kerapan Horsfieldia sp dan Calophylum sp sama yaitu sebesar $11,76 \%$. kemudian diikuti jenis lainnya. Sedangkan untuk fkrekwensi relatih untuk jenis tegakan tiang yang sering muncul adalah Darmor (Sphtiostemon sp) dan Bintangor (Calophylum sp) yaitu sebesar 15,38\%, untuk jenis lainya relatif kecil yaitu sebesar $7,89 \%$.Pada tegakan tiang ini Darmor (Sphtiostemon sp) juga menepati luasan yang besar yaitu 53,75\% lebih mendominasi di bandingkan Margganipro (Horsfieldia $\mathrm{sp}$ ) yang menempati luasan wilayah sebesar $32,14 \%$ sedangkan untuk jenis lainnya dominansi relatif kecil dan dari pengamatan yang kami lakukan pertumbuhannya tersebar tidak merata. Nilai INP yang besar pada tegakan Darmor (Sphtiostemon sp) 98,55\%, ni memperlihatkan jenis ini cendrung menguasai pertumbuhan pada tingkatan tiang pada areal yang ada di banding dengan Horsfieldia sp dan Calophylum yang mempunyai INP $51,60 \%$ dan 28,57 apalagi di banding jenis lainnya yang relatif kecil, hal ini juga diperlihatkan oleh nilai kerapatan, frekwensi dan dominansi yang juga mempunya nilai tertinggi.

\section{Analisis Vegetasi Tingkat Pohon}

Hasil analisis vegetasi kerapatan, kerapatan relatif, fkrekwensi dan frekwensi relatif, dominansi, dominansi relatif dan INP pertumbuhan jenis tingkat pohon di sajikan pada table 4. 
Tabel 4. Struktur vegetasi pohon yang ditemukan di hutan dataran rendah Samares kampung Sepse distrik Biak Timur

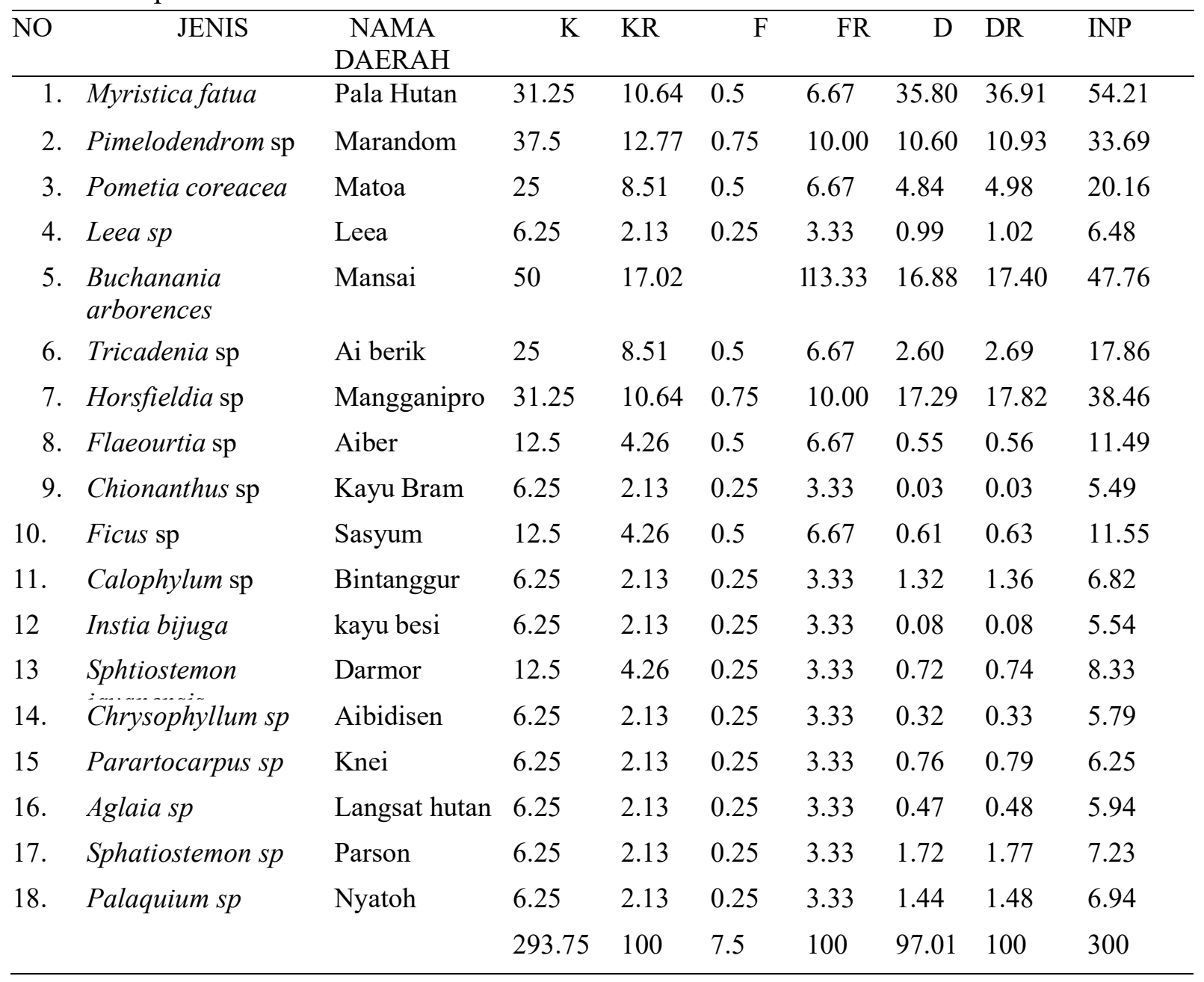

Dari hasil analisis vegetasi pada tabel 2, jenis vegetasi dari pohon yang mempunyai nilai kerapatan paling tinnggi terdapat di daerah area pengamatan adalah jenis Mansai (Buchanania arborences) sebesar 17,02 dikuti jenis Marandom (Pimelodendrom sp) setelah itu Pala hutan (Myristica fatua) dan Mangganipro (Horsfieldia sp) sebesar 10,64\%. Nilai kerapatan relatif yang besar dari Mansai (Buchanania arborences) dikarenakan jenis ini merupakan jenis-jenis pemenang dalam persaingan dan mempunyai toleransi yang lebar, sehingga persatuan luasnya akan dijumpai individu yang lebih besar. Pada tabel di atas terlihat bahwa jenis-jenis pohon yang mempunyai nilai Kehadiran relatif besar akan cenderung mempunyai nilai kerapatan relatif yang besar pula.

Mansai (Buchanania arborences) juga merupakan pohon yang tersebar cukup merata pertumbuhannya hal ini dapat di lihat sering munculnya jenis ini pada areal pengamatan dengan freksensi relatif sebesar 13,33\% setelah itu jenis Marandom (Pimelodendrom sp) dan Mangganipro (Horsfieldia sp). Penyebaran yang luas dari Mansai (Buchanania arborences) 
diduga karena jenis ini mempunyai toleransi yang lebar terhadap perbedaan kelembaban tanah yang ada dan faktor-faktor lingkungan yang lain. Untuk tumbuhan yang mempunyai toleran yang lebar, akan terdistribusi sangat luas sehingga nilai kehadiran relatifmya akan lebih tinggi dari yg lain, seperti apa yang dikemukakan oleh Soerianegara (1972) penyebaran jenis-jenis tumbuhan dalam komunitas merupakan reaksi (respon) yang berbeda dari jenis-jenis tersebut terhadap perbedaan mikro habitat. Di antara faktor-faktor lingkungan yang berpengaruh terhadap penyebaran tumbuhan maka kelembaban tanah (kandungan air) merupakan faktor yang paling berpengaruh.

Lain halnya pada tingkat dominansi, dalam hal ini Pala hutan (Myristica fatua) relatif lebih dominan di banding jenis lainnya, yaitu dengan dominansi relatif sebesar $36,91 \%$ sedangkan Buchanania arborences dan Horsfieldia sp dominansi relatifnya lebih kecil. Hal ini diduga Pala hutan (Myristica fatua) tersebut mampu untuk bersaing dengan jenis-jenis lain dalam mendapatkan sinar matahari dan unsur hara dalam tanah. Hal ini sesuai dengan pendapat Weaver and Clement (1938) yang dikutip oleh Iriatno (1984), penguasaan suatu jenis terhadap jenis yang lain ada hubungannya dengan pertumbuhan dari jenis-jenis tersebut. Jenisjenis yang mampu tumbuh dengan kuat dan cepat akan memperoleh cahaya yang lebih banyak sehingga akan menjadi lebih tebal dan dapat mengalirkan makanan dengan baik dan mampu menumbuhkan akar secara cepat. Kondisi ini menyebabkan suplai makanan yang lebih besar, penetrasi yang lebih dalam dan penyebaran yang lebih luas dari akar sehingga jenis-jenis tersebut akan memperoleh sumbersumber keperluan hidupnya (air, cahaya dan unsur hara) secara lebih baik dari pesaingnya. Hal ini menunjukkan karakteristik dari pala hutan yang mempunyai pengaruh penguasaan dalam areal tersebut terhadap jenis lain sehingga populasi jenis lain relatif akan berkurang dalam jumlah atau daya hidupnya (Ewusie, 1980).

Secara keseluruhan Pala hutan (Myristica fatua) menguasai areal yang ada, dengan INP sebesar 54,21\% lebih tinggi di banding Buchanania arborences dan Pimelodendrom sp. Hal ini memperlihatkan Pala hutan (Myristica fatua) mempunyai tingkat kepentingan atau peranan jenis tersebut dalam komunitas. Jenisjenis yang mempunyai peranan yang besar (dominan) dalam komunitas akan mempunyai INP tinggi. INP diperoleh dengan menjumlahkan nilai kehadira relatif, kerapatan relatif dan dominansi relatif. Karena INP ditentukan oleh ke-tiga relatif tersebut maka nilainya berkisar 0 sampai 300 (MuellerDombois dan Ellenberg, 1974).

\section{KESIMPULAN}

Analisis vegetasi yang dilakukan pada kawasan hutan dataran rendah Samares kampung Sepse ditemukan komposisi jenis sebanyak 29 jenis, dengan struktur vegetasi bervariasi pada setiap tingkat pertumbuhannya. Struktur vegetasi pada pertumbuhan tingkat semai dan pancang kerapatan relatif tertinggi terdapat pada jenis kamomes (Garcinia sp) sedangkan pada tingkat tiang Darmor (Sphtiostemon sp) dan Mansai (Buchanania arborences) pada tingkat pohon, Sedangkan untuk frekwensi relatif tertinggi pada Aibidisen (Chrysophyllum sp) pada tingkat semai dan jenis Mandus (Macaranga sp), Mansai (Buchanania arborences sp) Jambu Hutan (Syzygium sp) pada tingkat pancang sedangkan pada tingkat tiang Darmor (Sphtiostemon sp) dan Bintangor (Calophylum sp) dan Marandom (Pimelodendrom sp) dan Mangganipro (Horsfieldia sp) pada tingkat pohon. Berdasarkan nilai Indek Nilai Pentingnya ternyata Pala hutan (Myristica fatua) merupakan jenis yang paling berperan dalam komunitas dengan INP 54,21\%. Jenis-jenis lain 
yang termasuk dominan adalah Mansai (Buchanania arborence) dan Mangganipro (Horsfieldia sp).

\section{DAFTAR PUSTAKA}

Ashton PS. 1982. Dipterocarpaceae. In: Van Steenis, C.G.G.J (ed.) Flora Malesiana (9): 237-552.

Anwar, J., Damanik S.J., Hisyam N., \& Whitten A.J. (1992). Ekologi Ekosistem Sumatera. Yogyakarta: Gadjah Mada University Press.

Ewusie JY. 1980. Pengantar ekologi tropika. Tanuwidjaya Usman, penerjemah. Bandung : ITB Press. Terjemahan dari : Elements of Tropical Ecology.

Heriyanto NM dan Subiandono E. 2007. Studi dan potensi Geronggang (Cratoxylon arboresccens $\mathrm{BI}$ ) di kelompok hutan sungai berpasir sungai Sidung, kabupaten Tanjung Redeb, Kalimantan Timur. Buletin Plasma Nutfah.Vol. 13 No. 2.

Iriatno H. 1984. Analisis vegetasi dan asosiasi antara jenis-jenis utama penyusun hutan suaka alam pegunungan di Cibodas (Problema Kehutanan). Fakultas Kehutanan UGM. Yogyakarta.
Mongabay. 2012. Hutan dataran rendah. Diperoleh dari http://www.mongabay.co.id/hutan- dataranrendah, pada 11 Oktober 2017.

Mueller-Dombois, D dan H. Ellenberg. 1974. Aims and methods of vegetation ecology. John Wiley and Sons . New York.

Pamulardi, B. (1999). Hukum Kehutanan dan Pembangunan Bidang Kehutanan. Jakarta: PT Raja Grafindo Persada.

Purwaningsih. 2004. Sebaran ekologi jenisjenis Dipterocarpaceae di Indonesia. Biodiversitas Journal, 5 (2), 89-95.

Soerianegara I. 1972. Ekologi hutan Indonesia. Departemen Management Hutan Fakultas Kehutanan IPB. Bogor.

Soerianegara I dan Indrawan A. 2016. Ekologi Hutan Indonesia. Departemen Manajemen Hutan Fakultas Kehutanan. Bogor: Institut Pertanian Bogor.

Undang-Undang Republik Indonesia. 2013. Undang-Undang Nomor 18 Tahun 2013 Tentang Pencegahan Pemberantasan Perusakan Hutan. Kementerian Sekretariat Negara Repoblik Indonesia.

Weaver JE and Clement PE. 1938. Plant ecology. New York : McGRaw-Hill. 